\title{
Dual-Band Dual-Mode Textile Antenna/Rectenna for Simultaneous Wireless Information and Power Transfer (SWIPT)
}

\author{
Mahmoud Wagih, Graduate Student Member, IEEE, Geoffrey S. Hilton, \\ Alex S. Weddell, Member, IEEE, and Steve Beeby, Senior Member, IEEE
}

\begin{abstract}
This paper presents a textile antenna for dualband Simultaneous Wireless Information and Power Transfer (SWIPT). The antenna operates as a $2.4 \mathrm{GHz}$ off-body communications antenna and a sub-1 GHz $(785-875 \mathrm{MHz})$ broadbeam rectenna. Incorporated within the broadside microstrip antenna is a high-impedance rectenna for sub-1 $\mathrm{GHz}$ power harvesting. Utilizing antenna-rectifier co-design, the rectenna eliminates the rectifier matching network. The textile antenna is fabricated on a felt substrate and utilizes conductive fabrics for the antenna. At $2.4 \mathrm{GHz}$, the antenna achieves a realized gain of $7.2 \mathrm{dBi}$ on a body phantom and a minimum radiation efficiency of $63 \%$, with and without the rectifier. The rectenna achieves a best-in-class RF to DC efficiency of $62 \%$ from $0.8 \mu \mathrm{W} / \mathrm{cm}^{2}$, representing over $25 \%$ improvement over stateof-the-art textile rectennas and demonstrating that SWIPT does not detrimentally affect the energy harvesting or communications performance. The antenna/rectenna occupies an electrically-small area of $0.213 \times 0.19 \lambda_{0}^{2}$. This antenna is the first dual-band, dualmode antenna demonstrated on textiles for SWIPT applications and the first dual-band matching network-free SWIPT rectenna.
\end{abstract}

Index Terms-Antennas, Microstrip Antennas, Rectennas, RF Energy Harvesting, SWIPT, Wearable Antenna, Wireless Power Transfer

\section{INTRODUCTION}

W IRELESS communication in Body Area Networks (BANs) enables a variety of applications in healthcare monitoring, fitness tracking and localization. Wireless Power Transmission (WPT) [1], Radio Frequency Energy Harvesting (RFEH) [2], and Simultaneous Wireless Information and Power Transfer (SWIPT) [3] are methods of enabling batteryfree sustainable low-power Internet of Things (IoT) devices. In SWIPT, a single wave can be used to transmit information and power to the IoT device. SWIPT is often implemented using a single-band antenna, combined with time-based splitting or power-dividing mechanisms, to split the incident power

This paragraph of the first footnote will contain the date on which you submitted your paper for review. This work was supported by the European Commission through the EnABLES Project, funded under H2020-EU.1.4.1.2 grant number: 730957 and the UK Engineering and Physical Sciences Research Council (EPSRC) under Grant EP/P010164/1. Datasets used in ths work will be available at DOI: 10.5258/SOTON/D1777 (Corresponding author: M. Wagih)

M. Wagih, A. S. Weddell, and S. Beeby are with the School of Electronics and Computer Science, University of Southampton, Southampton, SO17 1BJ, U.K. (email: mahm1g15@ecs.soton.ac.uk)

G. S. Hilton is in the Communication Systems \& Networks Group, University of Bristol, Bristol BS8 1UB, U.K. (email: Geoff.Hilton@bristol.ac.uk) between rectifier and the information receiver [3]. Despite extensive research showing the performance benefits of SWIPT in networking, very limited antenna implementations have been specifically designed for simultaneous operation as communication and RFEH antennas.

A variety of antenna designs, from conventional and novel $50 \Omega$ antennas to high-impedance antennas designed in conjunction with the rectifier have been proposed for RF-powering [4]. Textile rectennas are mostly based on off-body antennas [5]-[9], due to their improved isolation. More recently, widebeam omnidirectional "wire-type" antennas such as monopoles were investigated for wearable applications [10]-[12]. While textile-based rectifiers have been used in [5] and [8], their Power Conversion Efficiency (PCE) has been lower than a rigid low-loss rectifier coupled to a textile patch antenna [7]. Furthermore, while a high-PCE sub- $\mu \mathrm{W} / \mathrm{cm}^{2}$ all-textile rectenna was presented in [10], its PCE plateaues below 55\% for higher power densities. The reported wearable rectennas have been exclusively focused on power reception and have not considered a SWIPT scenario.

In existing SWIPT rectenna and antenna designs, the common approach is to use two antennas in the same space [13] or a dual band antenna [14]. It is common to use a lower frequency band for down-link power transmission to the wireless-powered device, and a higher frequency for uplink information transmission to the base-station. This was proposed at $2.4 / 0.915 \mathrm{GHz}$ [15], 40/24 GHz [14], and 60/24 $\mathrm{GHz}$ [13]. A two-port $2.4 \mathrm{GHz}$ antenna was used in [16] to enable simultaneous communications and energy harvesting. Recently, a SWIPT rectenna has been proposed in [17] based on a high-isolation hybrid coupler. However, the size of the coupler is large compared to the antenna and a rectifier matching network is required at the antenna's input port. Furthermore, such a coupler on a lossy textile substrate would incur significant insertion losses reducing the harvested DC power.

To design a hybrid antenna/rectenna for wearable SWIPT, propagation in BANs needs to be reviewed. Antennas for body-centric communications are categorized into different modes of operation. First of all, off-body, where the wearable antenna communicates with a device or a base-station off the body [18]-[22]. Off-body antennas typically have broadside radiation patterns to minimize interaction with the body. The second mode is on-body communications, where two antennas mounted on the same user communicate across the body [23] 
[25], these antennas typically have omnidirectional radiation patterns with vertical polarization, or end-fire radiation patterns for point-to-point applications [24]. The final mode is in-body, where the wearable antenna communicates with an implant or is used for medical imaging [26].

Multiple wearable antenna designs, based on textile and non-textile materials, such as buttons and accessories, have been proposed for off-, on- and in-body applications. A ground plane or reflector-backing is often implemented to direct the antenna's main beam away from the body for offbody applications. On the other hand, on-body/omnidirectional antennas often resemble monopoles and have omnidirectional radiation patterns [10]. As for in-body antennas, either omnidirectional radiation patterns or high gain beams directed into the body are used. For example, in [27] an off-/in-body antenna combines two patch elements, one facing off the body and the other facing into the body, with a ground plane in between. Textile-based rectennas have been developed with broadside (off-body) radiation [5], [7]-[9], as well as omnidirectional radiation with no shielding from the body [10]-[12].

To improve the versatility of the wearable antennas, making them suitable for different off-, on-, and in-body applications simultaneously, multi-mode antennas have been proposed. Multiple antennas have been developed using textile dual and multi-mode antennas [27]-[36]. This has been achieved using multi-port antennas [32], [34], single-port antennas with multiple radiating elements [27], [28] as well as antennas with multiple resonant modes for multi-band and multi-mode operation with reconfigurable elements [37].

Nevertheless, all the reported wearable antennas were developed solely for communications or energy harvesting, and require a separate impedance matching network. In addition, the dual-radiation modes generated from the antennas are from standard $50 \Omega$ ports, even in the case of dual-port antennas [34]. Furthermore, complex impedance antennas, such as RFID antennas [38] or rectennas [4], have not been integrated in any dual-mode BANs antennas.

This paper presents the first dual-band dual-mode antenna combining a microstrip patch with a high-impedance codesigned rectenna for SWIPT applications, unlike our previous work in [39] where a single-band/mode SWIPT antenna was first demonstrated. The proposed antenna uses its broadside radiation pattern for $2.4 \mathrm{GHz}$ off-body communications and an omnidirectional radiation pattern for power reception in the sub-1 GHz Industrial Scientific Medical (ISM)-band. By choosing a lower ISM-band for power transmission, the higher path-loss can be avoided. Moreover, integrating a sub-1 GHz rectenna within a $2.4 \mathrm{GHz}$ microstrip patch overcomes the size limitation of a standalone sub-1 GHz WPT antenna. At $2.4 \mathrm{GHz}$, the antenna achieves a minimum measured radiation efficiency of $63 \%$, with and without the rectifier connected, and a gain of $7.2 \mathrm{dBi}$. The sub- $1 \mathrm{GHz}$ rectenna is electrically very compact $\left(0.03 \lambda^{2}\right)$ with over $25 \%$ peakPCE-improvement over state-of-the-art (SoA) textile rectennas for sub- $\mu \mathrm{W} / \mathrm{cm}^{2}$ RFEH. The textile implementation of the antenna, the high radiation efficiency and gain at $2.4 \mathrm{GHz}$, and the high energy harvesting efficiency and sensitivity show that a single antenna could be used to simultaneously power a

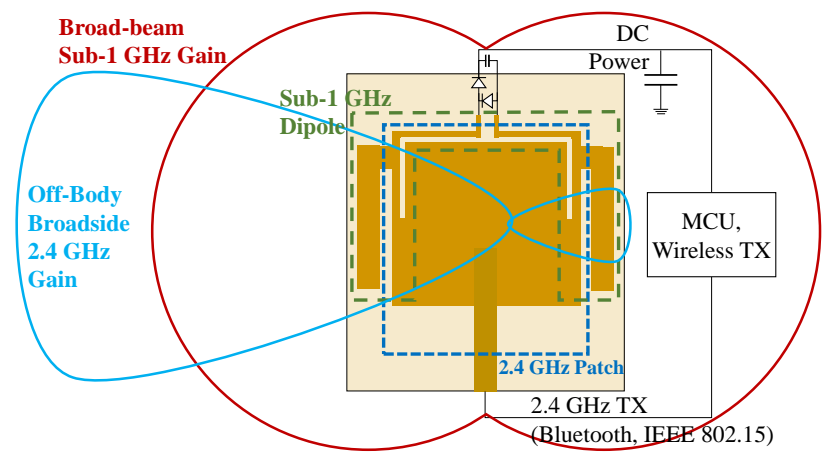

Fig. 1. The architecture of the proposed SWIPT antenna for sub-1 GHz WPT and $2.4 \mathrm{GHz}$ communications, with broadside and omnidirectional radiation patterns for the communication antenna and the rectenna, respectively.

sensor node while transmitting and receiving information from an off-body source.

\section{SWIPT ANTENNA Design AND Simulation}

\section{A. Dual-Band Dual-Mode Antenna}

The antenna design process is divided into two parts: the design of a $50 \Omega 2.4 \mathrm{GHz}$ antenna with broadside off-body radiation patterns, and the design of a broad-beam sub-1 $\mathrm{GHz}$ rectenna, due to the improved harvesting probability an omnidirectional antenna in sub-1 GHz bands [40]. Furthermore, sub-1 GHz rectifiers typically achieve a higher PCE [1]. For SWIPT to be efficient, the mutual coupling between the rectenna and the communication antenna needs to minimized. To illustrate, high mutual coupling would result in the 2.4 $\mathrm{GHz}$ transmitted power leaking to the rectifier, reducing the communication's range. Moreover, the rectenna's DC output may degrade if the sub-1 GHz incident power is absorbed by the $2.4 \mathrm{GHz}$ transceiver instead of the rectifier.

Fig. 1 shows the application of a the proposed antenna at a system level. The same dual-port fully-textile antenna can be utilized as a rectenna, without a matching network, to power wearable a microcontroller unit (MCU), sensors and a transceiver. The same antenna can then be used by the wireless transceiver to communicate with an off-body base-station. The scope of this work covers the antenna and rectenna design as opposed to the complete system implementation.

\section{B. Antenna/Rectenna Stepped Design and Simulations}

The first step in designing the antenna is the design of a standard $2.4 \mathrm{GHz}$ patch with a microstrip feed. The first iteration of the patch is based on the standard geometry to resonate at $2.4 \mathrm{GHz}$. A proximity-coupled microstrip feed is selected due to the high thickness of the felt fabric $(h=3.2 \mathrm{~mm})$ which will result in a probe-feed having high inductance [7]. The felt fabric falls within the $h>0.03 \lambda$ margin to achieve high radiation efficiency [41]. Furthermore, felt has a relatively low dissipation factor $(\tan \delta=0.02)$ compared to other woven textiles due to the larger air gaps in its composition [10]. The antenna was simulated in CST Microwave Studio to tune the length of the inset microstrip feed. Fig. 2 shows the design steps of the antenna, with step 1 being a common geometry 


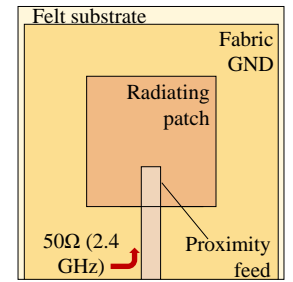

Step 1: Common patch
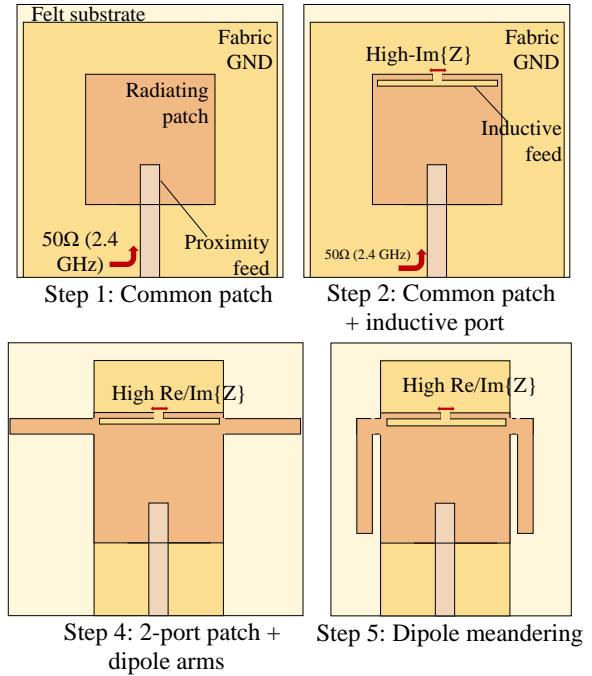

Step 2: Common patch + inductive port

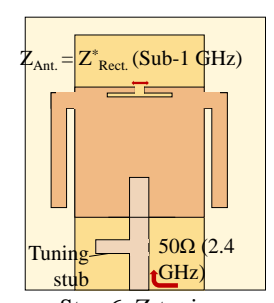

Step 6: Z-tuning

Fig. 2. Design steps of the proposed dual-band SWIPT antenna.

patch with the proximity-coupled feed, whose performance parameters are quote in Table I.

Step 2 is to introduce a second port for connecting the rectifier. While port- 2 could be directly connected to a microstrip line and a rectifier impedance matching network, antennarectifier co-design could be utilized to improve the impedance matching and subsequently the PCE [39]. For a single-series rectifier, the input impedance can be calculated analytically using

$$
Z_{\text {diode }}=\frac{V_{F}}{I_{\mathrm{dc}}}=\frac{V_{0} \sin \omega t-0.5 V_{\mathrm{DC}}}{I_{S}\left[B_{0}\left(\frac{V_{0}}{m V_{T}}\right) \exp \left(\frac{-0.5 V_{\mathrm{DC}}}{m V_{T}}\right)-1\right]},
$$

where $V_{F}$ and $V_{T}$ are the diode's forward voltage drop and the thermal voltage, $I_{S}$ is the diode's saturation current, $\omega$ is the angular frequency, $m$ is the diode's ideality factor and $B_{0}$ denotes the DC harmonic of the Bessel function describing the diode's current [42]. A high-accuracy estimate of the rectifier input impedance can be estimated for the low power region using Harmonic Balance (HB) simulation [43]. In [42], it was shown that for varying RF power levels and frequencies, the rectifier maintains a predominantly capacitive imaginary impedance.

As a result, an inductive feed is required, so a $1 \mathrm{~mm}$-wide slot is added at $1 \mathrm{~mm}$ from the top of the patch to introduce an inductive matching loop. The clearance of the slot form the top of the patch has been minimized to keep the antenna's foot-print small, and not to increase the resonant frequency of the $2.4 \mathrm{GHz}$ patch. A balanced port was used to simulate the antenna's input impedance looking into the inductive loop. The simulated input impedance at port- 2 shows a high complex impedance as shown in Table I.

Due to the size of the patch and the ground backing, almost all the accepted power at $868 \mathrm{MHz}$ at port-2 will dissipate in the dielectric substrate resulting in the very low radiation efficiency in step 2. To explain, the simulated dielectric losses in step 2 were over $95 \%$ of the accepted power. Therefore, the ground plane is miniaturized as in step 3 in Fig. 2. This reduces the capacitance of the loop and allows a reduced input

TABLE I

SUMMARY OF THE ANTENNA'S PARAMETERS FOR EACH DESIGN STAGE.

\begin{tabular}{|l|l|l|l|l|}
\hline & $\begin{array}{l}2.4 \mathrm{GHz} \\
\mathrm{S}_{11}\end{array}$ & $\begin{array}{l}2.4 \mathrm{GHz} \\
\eta_{\text {Rad. }}\end{array}$ & $\begin{array}{l}868 \mathrm{MHz} \\
Z(\Omega)\end{array}$ & $\begin{array}{l}868 \mathrm{MHz} \\
\eta_{\text {Rad. }} \\
(\%)\end{array}$ \\
\hline \hline $\begin{array}{l}\text { Step 1: } \\
\text { common patch }\end{array}$ & $\begin{array}{l}<-20 \\
\mathrm{~dB}\end{array}$ & $69 \%$ & $\begin{array}{l}\text { single- } \\
\text { port }\end{array}$ & $\begin{array}{l}\text { single- } \\
\text { port }\end{array}$ \\
\hline $\begin{array}{l}\text { Step 2: Port-2 } \\
\text { added + loop }\end{array}$ & $-1.7 \mathrm{~dB}$ & $58 \%$ & $1.4+\mathrm{j} 183$ & $<0.01 \%$ \\
\hline $\begin{array}{l}\text { Step 3: GND } \\
\text { miniaturization }\end{array}$ & $-0.2 \mathrm{~dB}$ & $54 \%$ & $0.92+\mathrm{j} 182$ & $10.1 \%$ \\
\hline $\begin{array}{l}\text { Step 4: dipole } \\
\text { arms added }\end{array}$ & $-3.6 \mathrm{~dB}$ & $72 \%$ & $11+\mathrm{j} 307$ & $82 \%$ \\
\hline $\begin{array}{l}\text { Step 5: dipole } \\
\text { meandering }\end{array}$ & $-3.9 \mathrm{~dB}$ & $71 \%$ & $5+\mathrm{j} 337$ & $43 \%$ \\
\hline $\begin{array}{l}\text { Step 6: patch stub } \\
\text { matching }\end{array}$ & $-19 \mathrm{~dB}$ & $71 \%$ & $16+\mathrm{j} 396$ & $53 \%$ \\
\hline
\end{tabular}
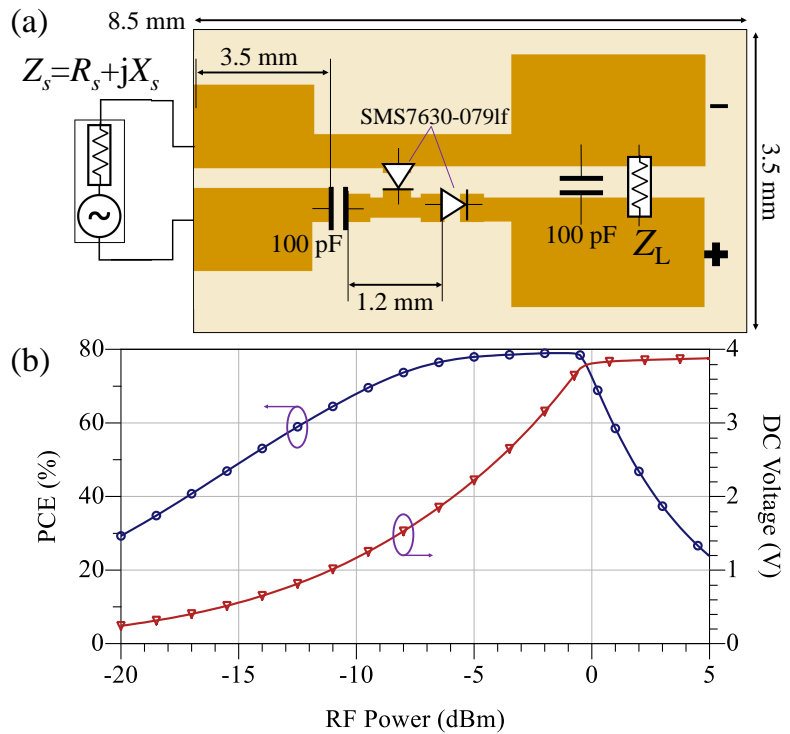

Fig. 3. The proposed voltage doubler rectifier: (a) layout and dimensions; (b) simulated DC voltage and PCE for a $20 \mathrm{k} \Omega$ load.

impedance. As a result, the radiation efficiency is significantly improved as in Table I.

The designed voltage doubler, shown in Fig. 3-a. achieves the maximum PCE between -20 and $-10 \mathrm{dBm}$ with a source of $Z_{\mathrm{S}}=30+j 330 \Omega$ impedance, at $868 \mathrm{MHz}$, obtained from the source/load optimization, where it was previously shown that optimizing the source and load impedance can achieve best-in-class PCEs at low power levels [44]. By designing the antenna to achieve an input impedance $Z_{\text {Antenna }}=Z_{S}^{*}$, the standalone impedance matching stage can be eliminated [4], [44], [45]. Fig. 3-b shows the HB-simulated PCE of the rectifier at $868 \mathrm{MHz}$, for a $20 \mathrm{k} \Omega$ load. The diode has been modeled using its datasheet junction and packaging parameters previously used in [10] where a close agreement between the simulated and measured results was observed.

From the rectifier's optimum source impedance of $30+j 330 \Omega$ Hence, the antenna's $\Re\{Z\}$ is too low to achieve a good impedance match. Furthermore, the low $\Re\left\{Z_{i n}\right\}$ implies a very low radiation efficiency due to the low radiation resistance. To improve $\Re\left\{Z_{i n}\right\}$, half-wavelength dipole arms 

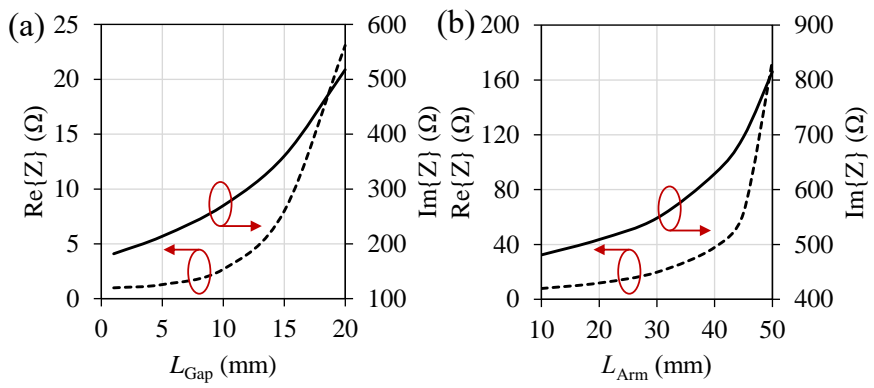

Fig. 4. Tuning the rectenna's (port-2) real (dashed) and imgainary (solid) impedance using (a) the gap, and (b) arm length.

are added in step 4 to prolong the current path bringing the input impedance at port- 2 closer to the input impedance of a standard half-wave dipole. Given that the horizontal dipole arms are not backed by the ground plane, the antenna fed at port- 2 should radiate through its dipole arm with high radiation efficiency. The length of the arms $L_{\mathrm{Arm}}$ can then be used to fine tune $\Re\{Z\}$. As in Table I, the added dipole arms significantly improve the radiation efficiency of the antenna.

While the dipole arms added bring the input impedance of port-2 to values within the range of a rectifier's input impedance, the arm's width is very long occupying additional space. The dipole arms could be redirected to make the antenna more compact without adversely reducing the radiation efficiency. In step 5, the dipole arms are folded to extend along the patch's length ( $E$-plane), reducing the width of the whole dual-band antenna from $120 \mathrm{~mm}$ to $75 \mathrm{~mm}$.

The final step is to tune the exact gap and dipole arms' length to match the impedance of the rectifier. The parametric tuning of $Z$ is shown in Fig. 4. It is observed that $L_{\text {Gap }}$ predominantly controls $\Im\{Z\}$ (the inductance), while $L_{\text {Arm }}$ controls the resonant frequency and therefore affects $\Re\{Z\}$. Fig. 6 shows the dimensions of the proposed antenna, and the tuning parameters. The parameters included on the final antenna prototype are $L_{\mathrm{Arm}}=48 \mathrm{~mm}$ and $L_{\mathrm{Gap}}=10 \mathrm{~mm}$. In simulation, it was found that for $L_{\text {Gap }}>10 \mathrm{~mm}$ and $L_{\text {Arm }}>40 \mathrm{~mm}$, the antenna maintains at least $50 \%$ radiation efficiency above $868 \mathrm{MHz}$. The simulated input impedance at the tunable- $Z$ port- 2 is shown in Fig. 5, showing the ability to tune the matching network-free rectenna by shifting the resonance frequency according to the required rectifier's $Z$.

As the antenna's geometry has been modified to match port-2 to the rectifier, the impedance matching of the patch is altered around $2.4 \mathrm{GHz}$. Therefore, additional tuning is required to restore resonance around $2.4 \mathrm{GHz}$ and match the patch to a $50 \Omega$ input. At $2.5 \mathrm{GHz}$, the antenna's impedance is $80 \Omega$, showing that it can be tuned using a real-impedance transformer. A shunt capacitive microstrip open stub is introduced on the feedline, as shown in step 6 in Fig. 2, to match the patch to $50 \Omega$. The length of the stub can be varied to tune port- 1 to $50 \Omega$ at $2.4 \mathrm{GHz}$ after the impedance of port2 is tuned to match a rectifier by varying $L_{\mathrm{Arm}}$ and $L_{\mathrm{Gap}}$. The tuned patch achieves a $\mathrm{S}_{11}<-19 \mathrm{~dB}$ at $2.4 \mathrm{GHz}$. The $>30 \mathrm{~dB}$ simulated and measured port isolation shows that the antenna can be used for simultaneously receiving power

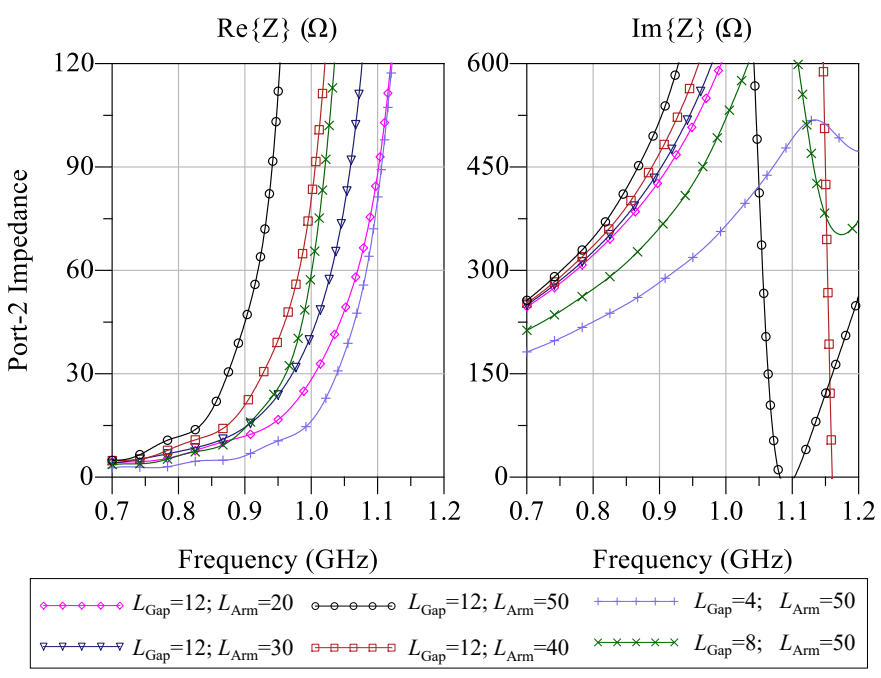

Fig. 5. Simulated input impedance of the antenna's rectifier port for different tuning parameters (dimensions in $\mathrm{mm}$ ).

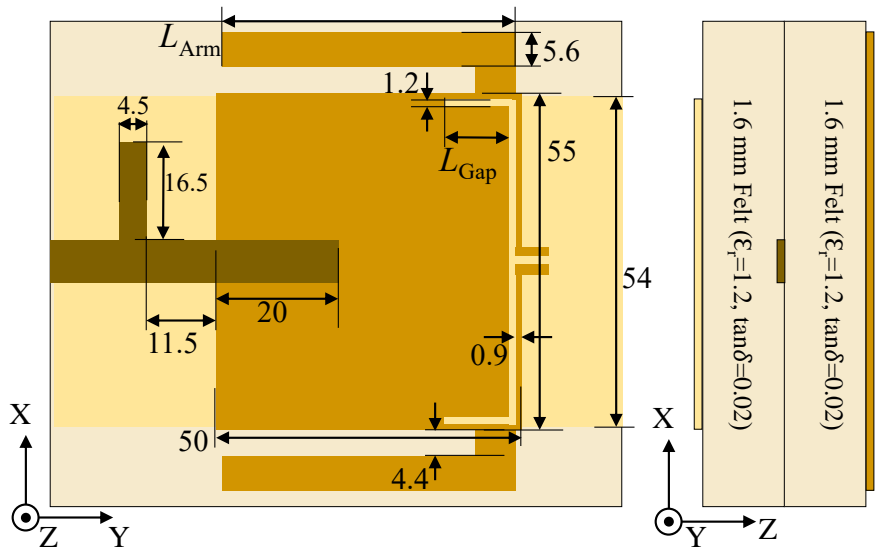

Fig. 6. Layout and dimensions (in $\mathrm{mm}$ ) of the proposed SWIPT antenna.

below $1 \mathrm{GHz}$ while the transceiver is active at $2.4 \mathrm{GHz}$ with minimal interaction. Finally, the antenna was simulated on an Austinman model [46], showing a low Specific Absorption Rate (SAR) complying with the IEEE C95.1 regulations, for the $10 \mathrm{gm}$ normalization weight. The $1.94 \mathrm{SAR}$, for $1 \mathrm{gm}$ tissue-normalization, can be reduced to sub-1.5 levels, by reducing the power input to the communications power by $1 \mathrm{~dB}$; it is expected that a $2.4 \mathrm{GHz}$ wearable Bluetooth or IEEE 802.15 transceiver would transmit at a power level under $20 \mathrm{dBm}$ due to their low-power nature.

\section{Antenna FABRication And MeAsurements}

\section{A. Antenna Fabrication}

The antenna was fabricated using adhesive-backed conductive fabric (P\&P MF copper and nylon weave) with a $0.12 \mathrm{~mm}$ measured thickness, patterned using laser cutting to create the antenna traces. The cutter used is the Epilog Mini 24 laser cutter with a $60 \mathrm{~W}$ CO2 laser, offering a 1200 dpi resolution; lower cost/resolution cutters can also be used as the antenna's dimensions are $>1 \mathrm{~mm}$. The sheet resistance of the conductive fabric was measured to be under $50 \mathrm{~m} \Omega /$ square, and to not 


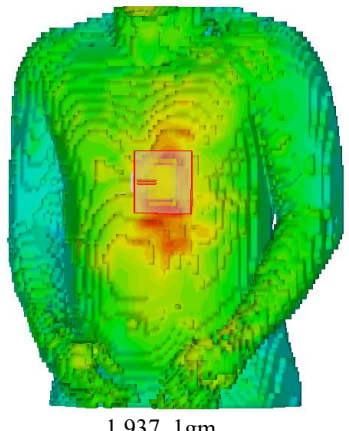

$1.937,1 \mathrm{gm}$

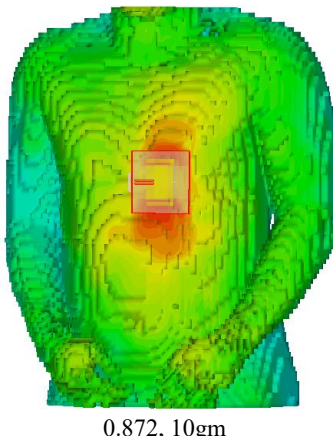

$0.872,10 \mathrm{gm}$

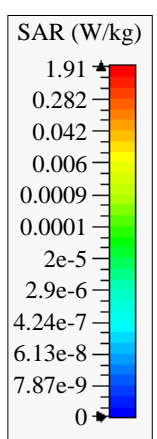

Fig. 7. Simulated SAR of the antenna at $2.4 \mathrm{GHz}$ showing the peak SAR, from $0.5 \mathrm{~W}$, when normalized to 1 and $10 \mathrm{gm}$ tissue mass.
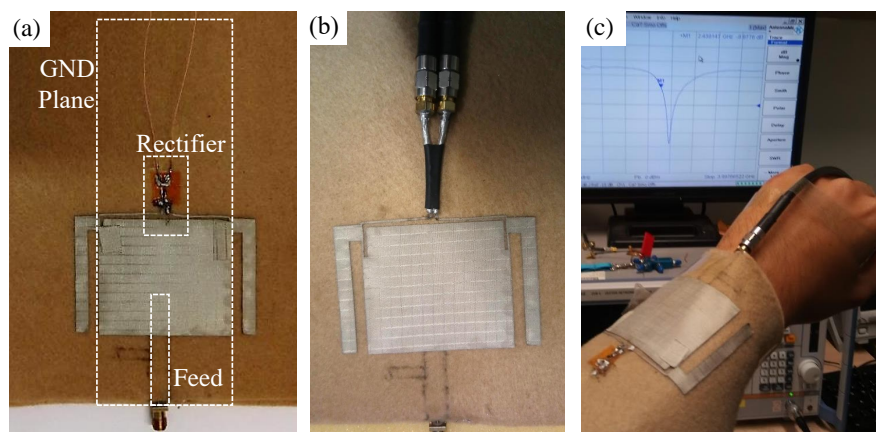

Fig. 8. Photographs of the textile SWIPT antenna: (a) the assembled prototype; (b) differential dipole impedance measurement; (c) $\mathrm{S}_{11}$ measurement on-wrist.

change after hand-washing and drying. Compared to polyimide copper laminates [9], conductive fabric is more user-friendly due to its breathability. Moreover, it does not require curing at a high temperature or is limited to certain substrates such as screen printing of conductive ink [7], in addition to achieving significantly higher conductivity than the ink in [47], with over $1 \Omega /$ square sheet resistance.

The rectifier was fabricated on a compact $25 \mu$ m-thick flexible polyimide substrate using photolithography, adhered to the textile using a 3M SprayMount repositionable adhesive, previously used in [10] and [7], resulting in an adhesive layer of approximately $10 \mu \mathrm{m}$ between the rectifier and the felt; the same adhesive was used for bonding the two felt layers shown in Fig. 6. It was previously shown that a rectifier fabricated using this technique can withstand over 250 bending cycles without notable degradation in its DC output, when encapsulated using a simple adhesive Kapton tape [10]. In addition, when encapsulated using vacuum-formed Kapton, textile-integrated RF circuits fabricated using this technique withstand over 30 machine washing cycles [48]. Fig. 8-a shows the assembled antenna/rectenna prototype.

\section{B. Antenna Input Impedance Measurements}

The reflection coefficient $\left(\mathrm{S}_{11}\right)$ at port-1 has been measured using a Rohde and Schwarz ZVB4 Vector Network Analyser (VNA) using a standard TOSM calibration. The measurements have been performed with an open circuit at port-2, as well as port-2 with the rectifier and DC load in place. Fig. 9 shows the

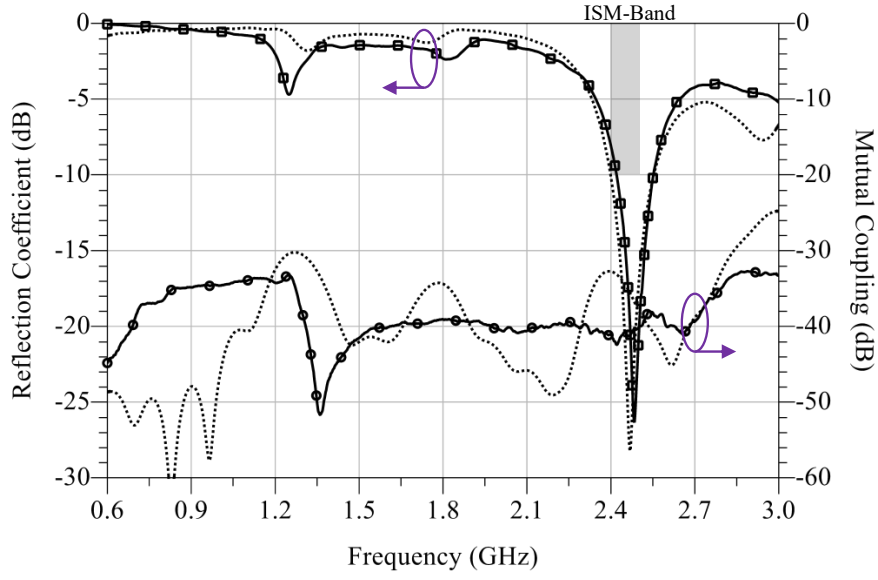

Fig. 9. Simulated (dashed) and measured (solid) s-parameters of the proposed textile antenna showing the $\mathrm{S}_{11}$ at the $2.4 \mathrm{GHz}$ communications port.

measured reflection coefficient of the antenna with $130 \mathrm{MHz}$ $S_{11}<-10 \mathrm{~dB}$ bandwidth covering the $2.4 \mathrm{GHz}$ ISM-band in both simulation and measurements. The simulated result in Fig. 9 was obtained on the Austinman phantom [46].

The mutual coupling between the communication and the rectifier ports was measured using an SMA connector mounted in place of the rectifier. In Fig. 9, the simulated and measured mutual coupling is below $-30 \mathrm{~dB}$, showing minimal interference in SWIPT. For instance, less than $30 \mathrm{~dB}$ of the transmitted power at $2.4 \mathrm{GHz}$ dissipate in the rectifier, showing that the simultaneous energy harvesting in sub- $1 \mathrm{GHz}$ will not reduce the radiated power.

The characterization of the rectifier's port is summarized in three steps: (a) measuring the differential input impedance; (b) measuring the mutual-coupling between the ports using a two-port VNA; (c) measuring the DC power leaking into the rectifier during active transmission on port- 1 .

To measure the input impedance at port-2, a two-port coaxial jig has been used to measure the differential impedance [49], as shown in Fig. 8-b. The simulated and measured input impedance at port-2 are shown in Fig. 10, demonstrating a close agreement between the simulation and measurements of $\Im\{Z\}$ below $1 \mathrm{GHz}$ (the target frequency band of the rectenna). A higher discrepancy is observed in $\Re\{Z\}$ due to additional resistive losses and due to inaccuracies in measuring the radiation resistance using balanced feeds. The impedance measurements of port-2 have been performed with port-1 terminated using a $50 \Omega$ SMA termination, to mimic the effects of an active impedance-matched transceiver IC.

The antenna, under flat and bent conditions, has been measured in human proximity as shown in Fig. 8-c. Fig. 11 shows the reflection coefficient and impedance of the antenna while bent around the arm on the $\mathrm{XZ}$ axis ( $H$-plane) and YZ axis ( $E$-plane), and when positioned on a user's chest (the measurements were performed in accordance with the University of Southampton's ethical committee approval, submission 54082, approved 05/02/2020). The antenna was then positioned on a user's wrist as shown in Fig. 8-c, resulting in a bending radius $\approx 3 \mathrm{~cm}$. For all configurations, it is observed that the input bandwidth, at port-1, is mostly unaffected. This 


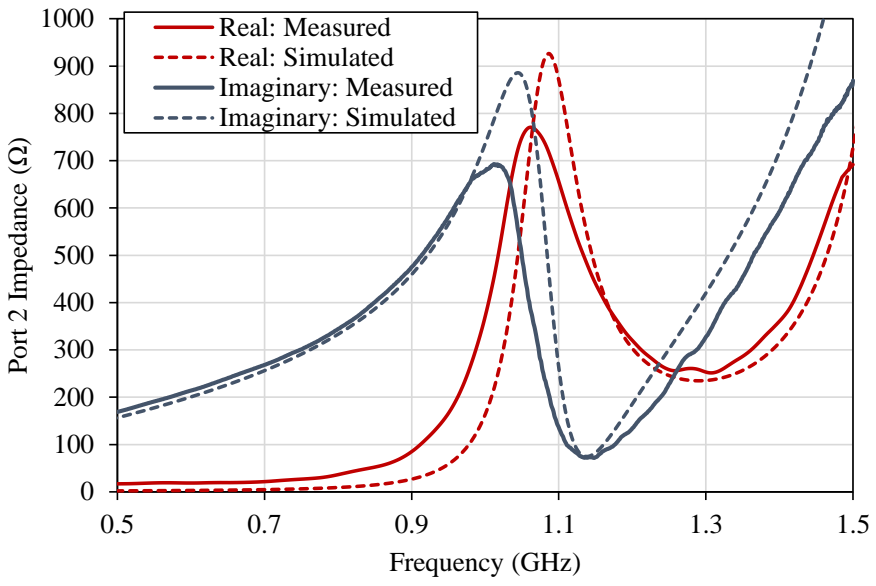

Fig. 10. Simulated (dashed) and measured (solid) input impedance at port-2.

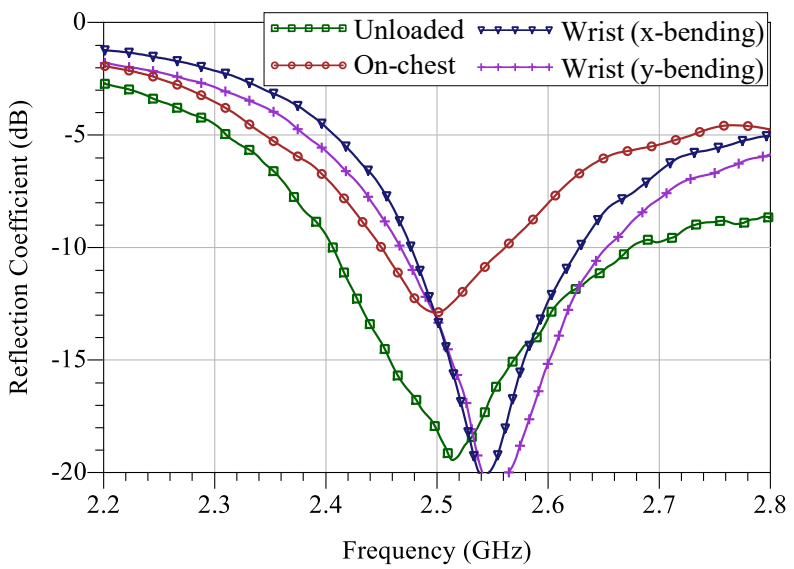

Fig. 11. Measured reflection coefficient of the antenna for different body parts.

demonstrates that the miniaturized ground plane-backing does not have a detrimental effect of the wearable performance of the $2.4 \mathrm{GHz}$ patch.

To further investigate the port coupling, the DC output of the rectifier was measured while injecting power into port1 , to mimic active wireless transmission. The measurements were performed at $830 \mathrm{MHz}$ (the rectenna's peak resonance), and $2.4 \mathrm{GHz}$ (the resonance of port-1). For $10 \mathrm{dBm}$ of power going into port-1, the DC voltage across an open load was below 510 and $550 \mathrm{mV}$, respectively. Based on the rectifier's simulation, this corresponds to less than $-15 \mathrm{dBm}$ of power being accepted by the rectifier. Therefore, the large-signal port isolation between the information transmission port (port-1) and the rectenna (port-2) is over $25 \mathrm{~dB}$, further verifying the high isolation between the communications and RFEH ports observed in Fig. 9.

\section{Antenna Radiation Properties Measurements}

The antenna's 3D polarimetric radiation patterns were measured on a body shadowing phantom in an anechoic chamber. The total efficiency $\eta_{\text {Tot. }}$ of the antenna (inclusive of mismatch) was calculated with respect to a reference monopole based on the total radiated power as in [50]. Fig. 12 shows
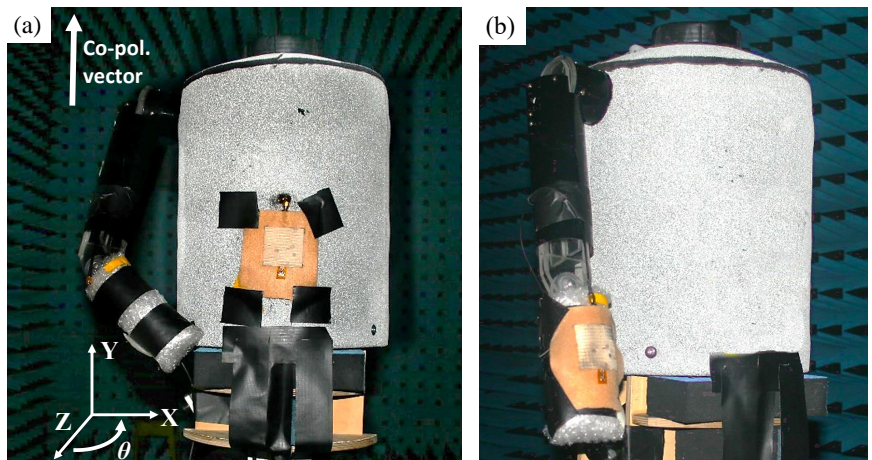

Fig. 12. Photographs of the measurement setup of the antenna showing the positioning on a body phantom in an anechoic chamber: (a) on-body setup; (b) on-arm setup.
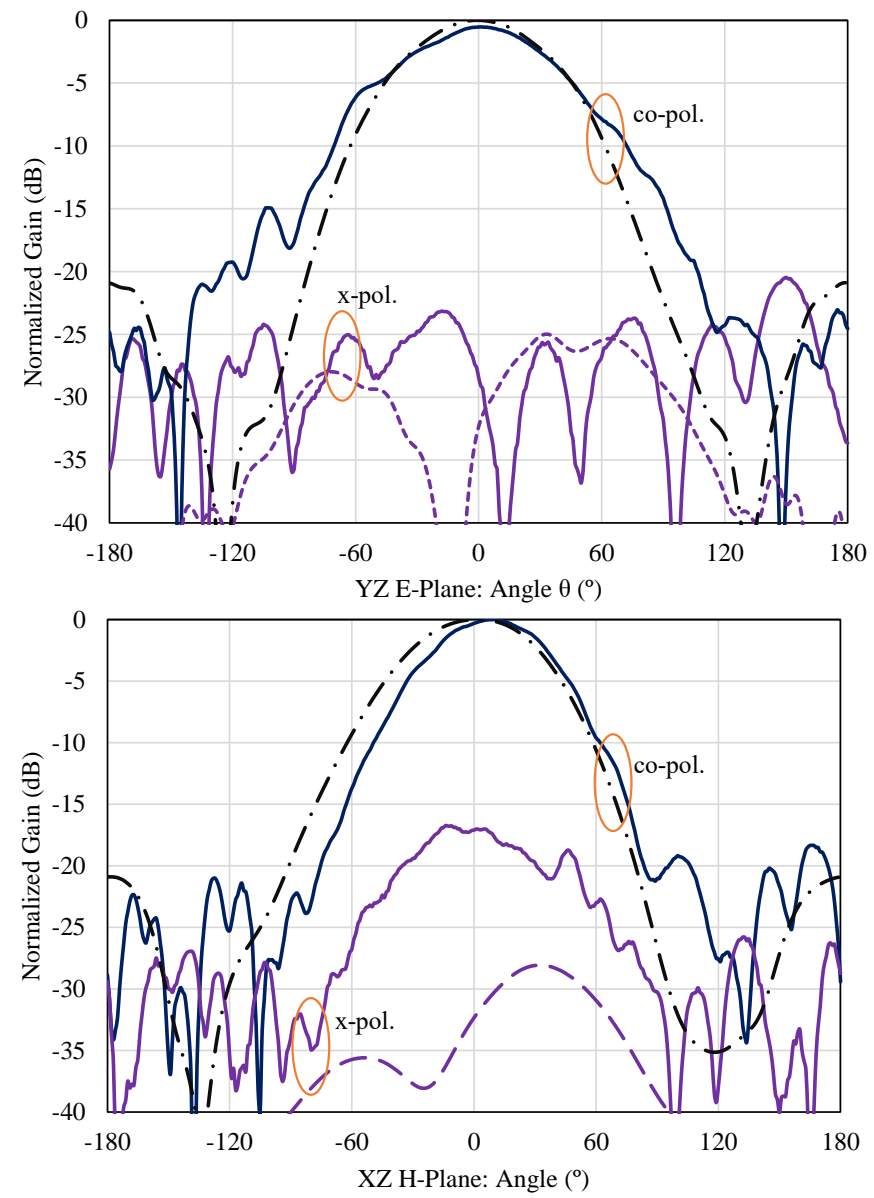

Fig. 13. Simulated (dashed) and measured (solid) patterns (normalized to $D=9.2 \mathrm{dBi}$ ) of the proposed SWIPT antenna, with a connected rectifier, at $2.4 \mathrm{GHz}$, on a phantom body (Fig. 12-a).

the antenna measurement setup on the phantom's body. The antenna's $\eta_{\text {Tot. }}$ at $2.4 \mathrm{GHz}$ is $66 \%$ and $63 \%$, before and after the rectifier is connected, respectively. The $0.2 \mathrm{~dB}$ difference between the measured gain, with and without the rectifier, highlights the minimal interaction between the rectifier and the 2.4 GHz antenna. Fig. 13 shows the normalized gain patterns on the $\mathrm{YZ}$ and $\mathrm{XZ}$ broadside $E$ - and $H$-planes. The directivity $D$ of the antenna is 9.2 and $9.3 \mathrm{dBi}$, with and without the 


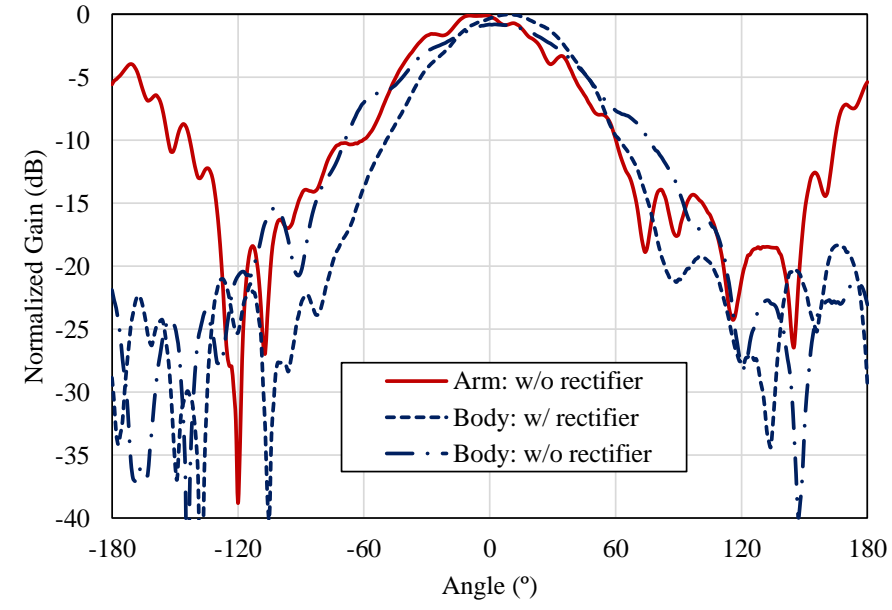

Fig. 14. Measured co-polarized normalized $E$-plane patterns of the antenna with (w/) and without (w/o) the rectifier on the phantom's body (Fig. 12-a) and arm (Fig. 12-b).

rectifier, respectively. This confirms that the rectifier does not affect the antenna's radiation properties. From the measured efficiency and directivity, the measured realized gain of the antenna is 7.2 and $7.5 \mathrm{dBi}$, with and without the rectifier, respectively.

From the measured patterns, it can be observed that the antenna is predominantly vertically-polarized, with $25 \mathrm{~dB}$ measured co-/cross-polarization isolation on the $E$-plane. On the $H$-plane, despite an increase in the cross polarization over the simulated values, the antenna still maintains over $15 \mathrm{~dB}$ polarization purity in the main broadside beam. However, this increase in the cross-polarized component has previously been reported for textile antennas measured on a body phantom [7], [35], and is not regarded as a disadvantage in off-body wearable communications [35].

The antenna's co-polarized patterns were measured on the phantom's arm as well as body, to show the additional offbody diffraction and shadowing effects. Fig. 12-b shows the on-arm test setup of the antenna. In addition, the antenna's patterns were measured for two prototypes, with and without the energy harvesting rectifier, to demonstrate that the rectifier does not affect the $2.4 \mathrm{GHz}$ antenna's patterns. Fig. 14 shows the measured $E$-plane co-polarized radiation patterns with and without the rectifier, as well as on-arm/body.

From Fig. 14, it can be confirmed that the inclusion of the rectifier not only has a minimal influence on the radiation efficiency, but also does not affect the main beam of the antenna. When the antenna is placed on-arm, additional diffraction and off-body reflection is expected, which results in an increase in the patterns behind the antenna. This however, does not affect the main beam significantly, and implies improved angular coverage behind the user when the patch is used on-arm. Multiple on-wrist positions and angular alignments can vary the off-body radiation pattern [50].

\section{ReCtenna MeAsurements}

To characterize the performance of the proposed rectenna, a wireless power source is used. As the rectenna's input

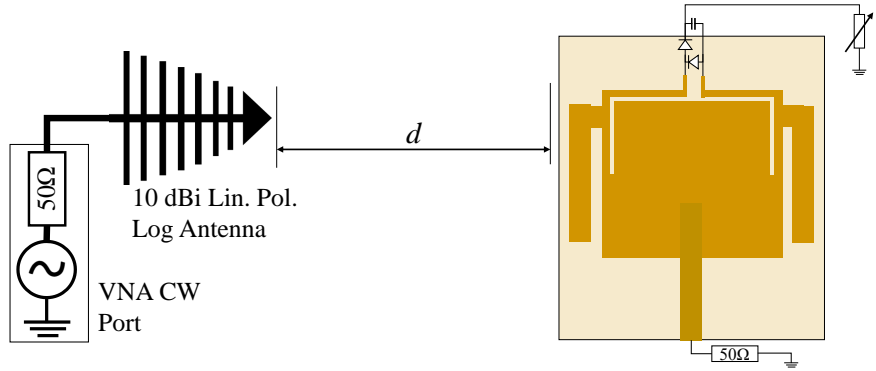

Fig. 15. Measurement setup of the rectenna using an incident plane wave.

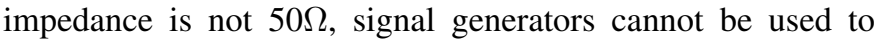
directly measure the rectifier's output with a coaxial feed. A $10 \mathrm{dBi} \log$ periodic antenna was connected to a VNA set to transmit a Continuous Wave (CW). The antenna was placed at $1.2 \mathrm{~m}$ from the source with the DC output connected to a variable resistive load and an oscilloscope (Agilent MSO7012B connected using a $\times 10$ Agilent N2862A probe). The distance between the transmitter and the receiver exceeds the minimum Fraunhofer far-field of $0.89 \mathrm{~m}$, for the $\log$ periodic antenna's length of $40 \mathrm{~cm}$. Fig. 15 shows the test setup of the proposed antenna, the same setup from [10] and [51]. The communications port was terminated using a $50 \Omega$ SMA termination.

The power available at the rectenna was calculated using the power density $S$ of the incident plane-wave and the antenna's effective area $A_{\mathrm{Eff}}$, calculated from the simulated gain at port2 [10]. The PCE of the rectenna is given by

$$
\mathrm{PCE}=\frac{V^{2}}{Z_{L}} \frac{1}{S A_{\mathrm{Eff}} .},
$$

where $V$ is the measured DC voltage across a load $Z_{L}$.

The first step in characterizing the rectenna is performing a frequency sweep at multiple $S$. From the measured $Z_{\text {Ant }}$. at port-2 (Fig. 10), the antenna is expected to match the rectifier around the $868 \mathrm{MHz}$ license-free band. Furthermore, due to operating further away from resonance, the antenna's response will be more broadband due to having a flatter impedance curve with frequency. Fig. 16 shows the measured broadband DC output of the rectenna across a $20 \mathrm{k} \Omega$ load. A highimpedance load is used to improve the voltage sensitivity of the rectenna while performing the broadband measurements to improve the accuracy for low $S$.

From Fig. 16, the rectenna achieves a half-power $(-3$ dB) fractional bandwidth of $11.5 \%$ from 780 to $875 \mathrm{MHz}$ covering the $868 \mathrm{MHz}$ EU license-free band. The broader bandwidth than the compact dipole in [44] is due to the more stable input impedance of the antenna shown in Fig. 10. Nevertheless, the measured PCE for $-20 \mathrm{dBm}$ received power, calculated from the incident power density, is $37 \%$ showing that the textile implementation does not degrade the high PCE achievable through antenna-rectifier co-design. Moreover, it is observed that for the $30 \times$ dynamic range of $S$ investigated, the rectenna's response is highly linear showing a very stable relative DC output for a wide dynamic range.

To maximize the harvested power, it is essential to identify the maximum power transfer point of the rectenna. A load 


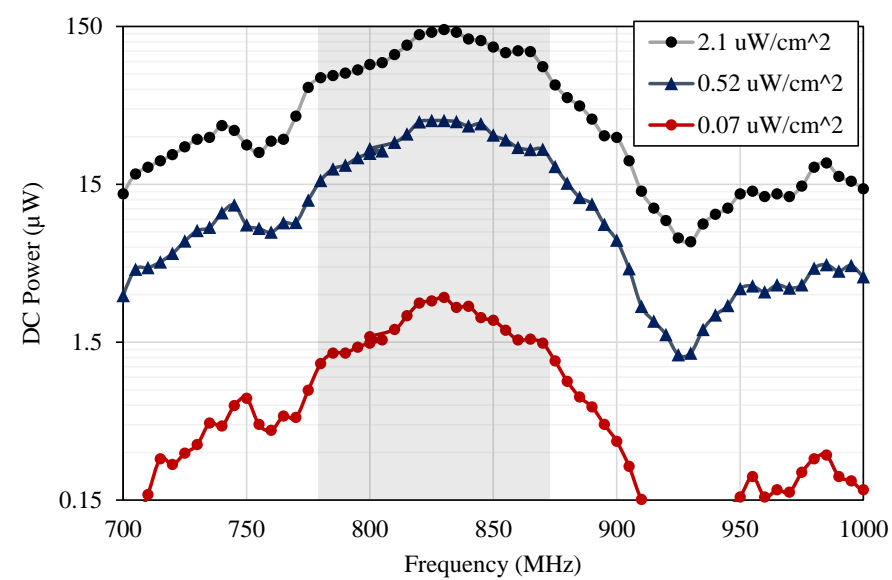

Fig. 16. Measured DC power harvested by the rectenna at varying frequencies for a $20 \mathrm{k} \Omega$ load; the shaded region indicates the half-power bandwidth.

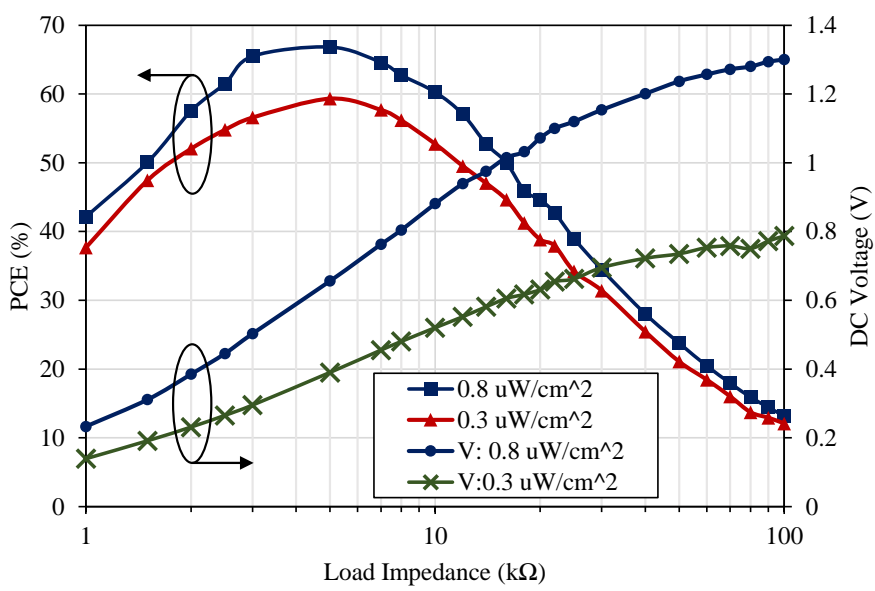

Fig. 17. Measured DC output of the rectenna, at $830 \mathrm{MHz}$, for varying resistive loads.

sweep was performed at two fixed power densities at 830 MHz. Fig. 17 shows the measured DC voltage and PCE of the rectenna at various loads from 1 to $100 \mathrm{k} \Omega$. For $S$ as low as $0.8 \mu \mathrm{W} / \mathrm{cm}^{2}$, the rectenna achieves a peak PCE of $67 \%$ with a $5 \mathrm{k} \Omega$ load, with over $0.65 \mathrm{~V}$ DC output. As with frequency, the optimum load of the rectenna is linear and does not vary for a lower $S$, showing that the proposed rectenna will maintain its maximum PCE when connected to a boost converter of a fixed input impedance, such as [7], without requiring Maximum Power Point Tracking (MPPT) capabilities.

After identifying the optimum frequency and $Z_{L}$ of the rectenna, a power sweep is carried out to investigate the rectenna's performance for varying $S$. Fig. 18 shows the measured DC output of the rectenna for $0.01<S<2 \mu \mathrm{W} / \mathrm{cm}^{2}$. The power sweep is carried out with a high-impedance $(20 \mathrm{k} \Omega)$ and an optimal $(8 \mathrm{k} \Omega)$ load. This shows the rectenna's performance for use cases where a high DC voltage sensitivity or a PCE are preferred, respectively.

It is observed that in the non-linear region of the rectenna (Fig. 18-b), the PCE exceeds $40 \%$ from less than $0.1 \mu \mathrm{W} / \mathrm{cm}^{2}$. The peak PCE of the rectenna is reached below $1 \mu \mathrm{W} / \mathrm{cm}^{2}$
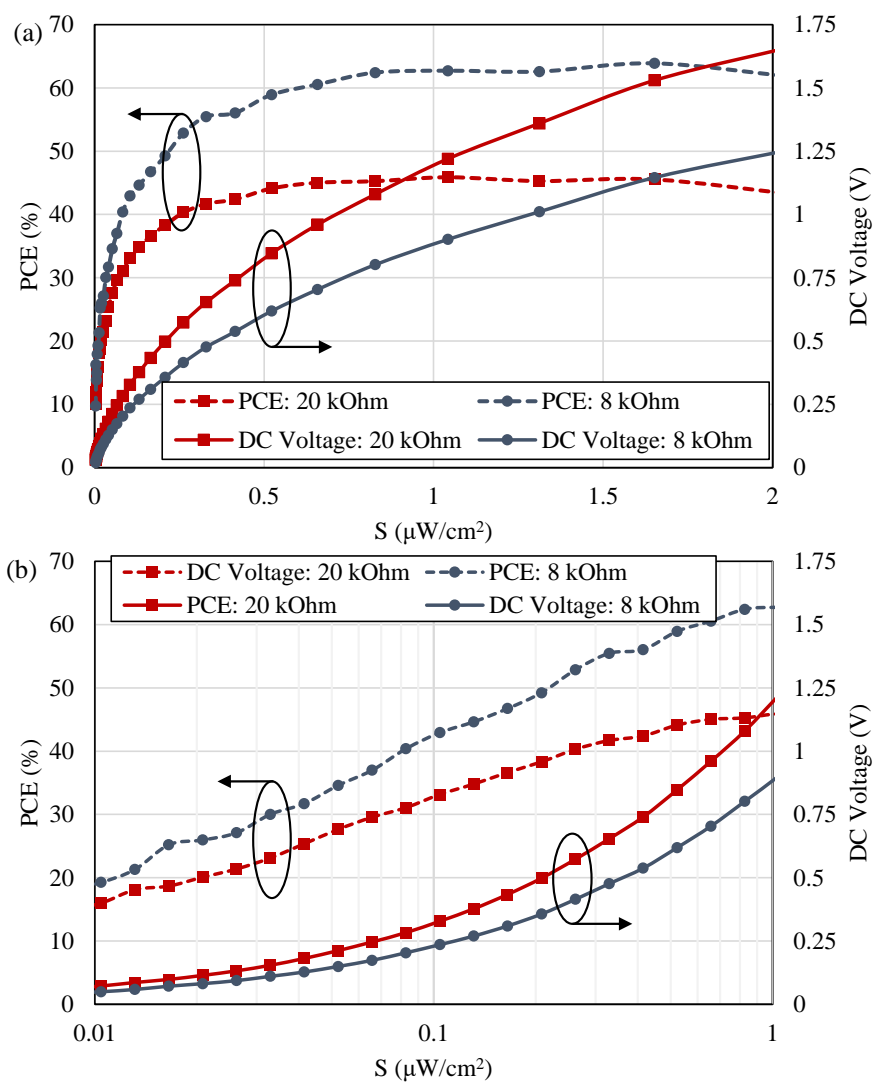

Fig. 18. Measured PCE and DC voltage output of the rectenna for a varying $S$ at an optimal $(8 \mathrm{k} \Omega)$ and a high impedance $(20 \mathrm{k} \Omega)$ load for a wide $S$ range (a) and low $S$ (b).

showing a high sensitivity and suitability for low-power RFEH. For a $20 \mathrm{k} \Omega$ load (16.5 $\mu \mathrm{A}$ current draw), a typical average current draw for a duty-cycled low-power wireless sensor node [52], the rectenna produces $330 \mathrm{mV}$, the voltage required to start a commercial BQ25504 boost converter [16], [53], from $S=0.1 \mu \mathrm{W} / \mathrm{cm}^{2}$. This represents $6 \times$ sensitivity improvement over [53], for a non-textile rectenna requiring $S=0.6 \mu \mathrm{W} / \mathrm{cm}^{2}$ to produce the required $330 \mathrm{mV}$. In addition, the DC power output is sufficient for various low-power computations as shown in [54], based on a commerciallyavailable MSP430 MCU.

Table II compares the proposed antenna/rectenna to SoA wearable and textile antennas and rectennas. This paper presents the only antenna designed specifically for SWIPT. Compared to other textile rectennas, [5], [10], [11], the proposed rectenna achieves the highest peak PCE with at least $5 \times$ sensitivity improvements compared to [5], operating in the same band, by requiring a significantly lower $S$ to reach the maximum PCE. While [7] achieves a high peak PCE, the rectifier uses a matching network implemented on a low-loss rigid substrate. While [10] achieves a better sensitivity, its peak PCE is $20 \%$ lower than this work, due to being specifically matched to a low power level using a lossy lumped inductor. Finally, considering the sub-1 $\mathrm{GHz}$ frequency of operation, the rectenna's electrical area is very small compared to SoA textile rectennas, owing to the meandered dipole-like radiating arms and the built-in inductive tuning loop. 
TABLE II

COMPARISON OF THE PROPOSED TEXTILE SWIPT ANTENNA WITH REPORTED TEXTILE ANTENNAS.

\begin{tabular}{|c|c|c|c|c|c|c|c|c|c|}
\hline Study & Application & Substrate & Frequency & $\begin{array}{l}\text { Comm. } \\
\text { Gain }\end{array}$ & $\begin{array}{l}\text { Rectenna } \\
\text { Gain }\end{array}$ & $\begin{array}{l}\text { Total Effi- } \\
\text { ciency }\end{array}$ & $\begin{array}{l}\text { Sensitivity } \\
\text { (min. } S \text { for } \\
\text { peak PCE) }\end{array}$ & Peak PCE & $\begin{array}{l}\text { Electrical } \\
\text { size }\left(\lambda_{0}\right)\end{array}$ \\
\hline This work & SWIPT & $\begin{array}{l}\text { felt, } \\
\tan \delta=0.02\end{array}$ & 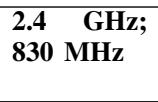 & $7.2 \mathrm{dBi}$ & $1.7 \mathrm{dBi}$ & $63 \% *$ & $\begin{array}{l}\mathbf{0 . 8} \\
\mu \mathrm{W} / \mathrm{cm}^{2}\end{array}$ & $63.9 \%$ & $\begin{array}{ll}0.213 & \times \\
0.190 & \times \\
0.009 & \\
\end{array}$ \\
\hline $\begin{array}{l}\text { TAP'20 } \\
{[10]}\end{array}$ & WPT & $\begin{array}{l}\text { felt, } \\
\tan \delta=0.02\end{array}$ & $830 \mathrm{MHz}$ & NA & $0.6 \mathrm{dBi}$ & NR & $\begin{array}{l}0.5 \\
\mu \mathrm{W} / \mathrm{cm}^{2}\end{array}$ & $53.3 \%$ & $\begin{array}{l}0.330 \\
0.330 \\
0.00027\end{array}$ \\
\hline $\begin{array}{l}\text { TAP'20 } \\
\text { [35] }\end{array}$ & $\begin{array}{l}\text { Communi- } \\
\text { cation }\end{array}$ & $\begin{array}{l}\text { felt, } \\
\tan \delta=0.01\end{array}$ & $2.45 \mathrm{GHz}$ & $7.5 \mathrm{dBi}$ & NA & $83 \%^{\dagger \ddagger}$ & NA & NA & $\begin{array}{l}0.544 \\
0.544 \\
0.016\end{array}$ \\
\hline $\begin{array}{l}\text { TMTT'20 } \\
\text { [11] }\end{array}$ & WPT & $\begin{array}{l}\text { poly-cotton, } \\
\tan \delta: \quad \mathrm{NR} \\
\approx 0.02\end{array}$ & $2-5 \mathrm{GHz}$ & NA & $-20 \mathrm{dBi}^{* *}$ & NR & $\begin{array}{l}100 \\
\mu \mathrm{W} / \mathrm{cm}^{2}\end{array}$ & $32 \%$ & $\begin{array}{l}>1.00 \\
1.00 \\
0.0006\end{array}$ \\
\hline $\begin{array}{l}\text { TMTT'18 } \\
\text { [7] }\end{array}$ & WPT & $\begin{array}{l}\text { felt, } \\
\tan \delta=0.023^{\diamond}\end{array}$ & $2.45 \mathrm{GHz}$ & NA & $6.8 \mathrm{dBi}$ & $66 \%$ & NR & $64.6 \%$ & $\begin{array}{l}0.740 \\
0.390 \\
0.028\end{array}$ \\
\hline TAP'13 [5] & WPT & $\begin{array}{l}\text { pile, jeans } \\
\tan \delta=0.018\end{array}$ & $830 \mathrm{MHz}$ & NA & $4.6 \mathrm{dBi}$ & NR & $3 \mu \mathrm{W} / \mathrm{cm}^{2}$ & $53.3 \%$ & $\begin{array}{l}0.702 \\
0.556 \\
0.0088\end{array}$ \\
\hline
\end{tabular}

NA: not applicable; NR: not reported; ${ }^{*}$ on-body efficiency; ${ }^{* *}$ evaluated from the graphs; ${ }^{\dagger}$ unloaded efficiency; ${ }^{\ddagger}$ exclusive of mismatch; ${ }^{\diamond}$ Antenna substrate rectifier on low-loss Rogers substrate

Not included in the comparison table is the dual-port $5.8 \mathrm{GHz}$ SWIPT rectenna in [17], due to being implemented on a low-loss rigid substrate. Nevertheless, the proposed rectenna achieves a higher peak PCE of $63.9 \%$ compared to $51.1 \%$ in [17]. In addition, this work presents over $10 \mathrm{~dB}$ rectenna sensitivity improvement over [17] by reaching $60 \%$ PCE from $-10 \mathrm{dBm}$ received power, calculated using (2), compared to approximately $32 \%$ by [17], while not requiring a stand-alone rectifier matching network.

\section{CONCLUSION}

This paper presented a textile dual-band dual-mode antenna for SWIPT applications, the first multi-band microstrip antenna with a matching network-less co-designed rectenna for RFEH. This work has shown than an antenna-based solution could enable switching-free and power splitting-free SWIPT in future wireless networks.

The proposed antenna/rectenna integrates a high impedance sub-1 GHz co-designed antenna and a rectifier within an offbody proximity-fed patch with a miniaturized ground plane. The proposed antenna achieves an input bandwidth covering the $2.4-2.5 \mathrm{GHz}$ ISM-band with a gain of $7.2 \mathrm{dBi}$ on a human phantom and at least $63 \%$ total efficiency. The antenna maintains a measured stable impedance response and radiation patterns when used on different body parts. Owing to the rectifier's differential inductive feed, the isolation between the rectenna and the communications antenna is over $30 \mathrm{~dB}$. The sub- $1 \mathrm{GHz}$ rectenna achieves a $63.9 \%$ PCE with $650 \mathrm{mV}$ DC output from a power density below $0.8 \mu \mathrm{W} / \mathrm{cm}^{2}$, demonstrating its suitability for ultra-low power RFEH applications. The proposed dual-band/mode SWIPT antenna is a prime candidate for battery-less BANs due to its high antenna and rectenna efficiency and gain, stable wearable performance, and small form factor.

\section{REFERENCES}

[1] C. R. Valenta and G. D. Durgin, "Harvesting Wireless Power: Survey of Energy-Harvester Conversion Efficiency in Far-Field, Wireless Power Transfer Systems," IEEE Microw. Mag., vol. 15, 4, pp. 108-120, 2014.

[2] X. Lu, P. Wang, D. Niyato, D. I. Kim, and Z. Han, "Wireless Networks With RF Energy Harvesting: A Contemporary Survey," IEEE Communications Surveys \& Tutorials, vol. 17, 2, pp. 757 - 789, 2015.

[3] T. D. P. Perera, D. N. K. Jayakody, S. K. Sharma, S. Chatzinotas, and J. Li, "Simultaneous Wireless Information and Power Transfer (SWIPT): Recent Advances and Future Challenges," IEEE Communication Surveys and Tutorials, vol. 20, 1, pp. 264 - 302, 2018.

[4] M. Wagih, A. S. Weddell, and S. Beeby, "Rectennas for RF Energy Harvesting and Wireless Power Transfer: a Review of Antenna Design [Antenna Applications Corner]," IEEE Antennas Propag. Mag., vol. 62 no. 5 , pp. $95-107,2020$.

[5] G. Monti, L. Corchia, and L. Tarricone, "UHF Wearable Rectenna on Textile Materials," IEEE Trans. Antennas. Propag., vol. 61, 7, pp. 3869 - 3873, 2013.

[6] K. W. Lui, O. H. Murphy, and C. Toumazou, "A Wearable Wideband Circularly Polarized Textile Antenna for Effective Power Transmission on a Wirelessly-Powered Sensor Platform," IEEE Trans. Antennas Propag., vol. 61 no. 7, pp. 3873 - 3876, 2013.

[7] S.-E. Adami, P. Proynov, G. S. Hilton, G. Yang, C. Zhang, D. Zhu, Y. Li, S. P. Beeby, I. J. Craddock, and B. H. Stark, "A Flexible 2.45GHz Power Harvesting Wristband With Net System Output From -24.3 dBm of RF Power," IEEE Trans. Microw. Theory Techn., vol. 66 no. 1, pp. 380-395, 2018.

[8] D. Vital, S. Bhardwaj, and J. L. Volakis, "Textile Based Large Area RF-Power Harvesting System for Wearable Applications," IEEE Trans. Antennas Propag., vol. 68, no. 3, pp. 2323 - 2331, 2019.

[9] M. Wagih, G. S. Hilton, A. S. Weddell, and S. Beeby, "Broadband Millimetre-Wave Textile-based Flexible Rectenna for Wearable Energy Harvesting ," IEEE Trans. Microw Theory Techn, vol. 68 no. 11, pp. 4960 - 4972, 2020.

[10] M. Wagih, A. S. Weddell, and S. Beeby, "Omnidirectional DualPolarized Low-Profile Textile Rectenna with over 50\% Efficiency for Sub- $\mu \mathrm{W} / \mathrm{cm}^{2}$ Wearable Power Harvesting," IEEE Trans. Antennas Propag., vol. Early Access, 2020.

[11] J. A. Estrada, E. Kwiatkowski, A. Lpez-Yela, M. Borgos-Garca, D. Segovia-Vargas, T. Barton, and Z. Popovi, "An RF-Harvesting Tightly-Coupled Rectenna Array Tee-Shirt with Greater than Octave Bandwidth," IEEE Trans. Microw. Theory Techniq., vol. 68 no. 9, pp. 3908 - 3919, 2020.

[12] M. Wagih, N. Hillier, S. Yong, A. S. Weddell, and S. Beeby, "Rfpowered wearable energy harvesting and storage module based on e- 
textile coplanar waveguide rectenna and supercapacitor," IEEE Open Journal of Antennas and Propagation, vol. 2, pp. 302 - 314, 2021.

[13] M. Tabesh, N. Dolatsha, A. Arbabian, and A. M. Niknejad, "A PowerHarvesting Pad-Less Millimeter-Sized Radio," IEEE Journal of SolidState Circuits, vol. 50, 4, pp. 962 - 977, 2015.

[14] P. Burasa, T. Djerafi, N. G. Constantin, and K. Wu, "On-Chip DualBand Rectangular Slot Antenna for Single-Chip Millimeter-Wave Identification Tag in Standard CMOS Technology," IEEE Trans. Antennas Propag., vol. 65 no. 8, pp. 3858 - 3868, 2017.

[15] G. Papotto, F. Carrara, A. Finocchiaro, and G. Palmisano, "A 90nm CMOS 5-Mbps Crystal-Less RF-Powered Transceiver for Wireless Sensor Network Nodes," IEEE Journal of Solid-State Circuits, vol. 49, 2, pp. 335 - 346, 2014.

[16] J. Bito, R. Bahr, J. G. Hester, S. A. Nauroze, A. Georgiadis, and M. M. Tentzeris, "A Novel Solar and Electromagnetic Energy Harvesting System With a 3-D Printed Package for Energy Efficient Internet-ofThings Wireless Sensors," IEEE Trans. Microw. Theory Techn., vol. 65 no. 5, pp. 1831 - 1842, 2017.

[17] P. Lu, C. Song, and K. M. Huang, "A Two-Port Multi-Polarization Rectenna with Orthogonal Hybrid Coupler for Simultaneous Wireless Information and Power Transfer (SWIPT)," IEEE Trans. Antennas Propag., vol. 68 no. 10 , pp. 6893 - 6905, 2020.

[18] K. Turbic, L. M. Correia, and M. Beko, "A Channel Model for Polarized Off-Body Communications With Dynamic Users," IEEE Trans. Antennas Propag., vol. 67 no. 11, pp. 7001 - 7013, 2019.

[19] N. Chahat, M. Zhadobov, S. A. Muhammad, L. L. Coq, and R. Sauleau, "60-GHz Textile Antenna Array for Body-Centric Communications," IEEE Trans. Antennas Propag., vol. 61 no. 4, pp. 1816 - 1824, 2013.

[20] P. Sambandam, M. Kanagasabai, R. Natarajan, M. G. N. Alsath, and S. Palaniswamy, "Miniaturized Button like WBAN Antenna for Off body Communication," IEEE Trans. Antennas Propag., vol. 68 no. 7, pp. 5228 - 5235, 2020

[21] P. B. Samal, P. J. Soh, and G. A. E. Vandenbosch, "UWB All-Textile Antenna With Full Ground Plane for Off-Body WBAN Communications," IEEE Trans. Antennas Propag., vol. 62 no. 1, pp. $102-108$, 2014.

[22] G.-P. Gao, C. Yang, B. Hu, R.-F. Zhang, and S.-F. Wang, "A Wearable PIFA With an All-Textile Metasurface for $5 \mathrm{GHz}$ WBAN Applications," IEEE Antennas Wireless Propag. Lett., vol. 18, no. 2, pp. 288 - 292, 2019.

[23] C. Mendes and C. Peixeiro, "On-Body Transmission Performance of a Novel Dual-Mode Wearable Microstrip Antenna," IEEE Trans. Antennas Propag., vol. 66 no. 9, pp. 4872 - 4877, 2018.

[24] N. Chahat, M. Zhadobov, L. L. Coq, and R. Sauleau, "Wearable Endfire Textile Antenna for On-Body Communications at $60 \mathrm{GHz}$," IEEE Antennas Wireless Propag. Lett., vol. 11, pp. 799 - 802, 2012.

[25] A. Alemaryeen and S. Noghanian, "On-Body Low-Profile Textile Antenna With Artificial Magnetic Conductor," IEEE Trans. Antennas Propag., vol. 67 no. 6, pp. 3649 - 3656, 2019.

[26] M. Srestniemi, C. Pomalaza-Rez, T. Kumpuniemi, M. Hmlinen, R. Kovacs, and J. Iinatti, "Measurement Data-Based Study on the Intrabody Propagation in the Presence of the Sternotomy Wires and Aortic Valve Implant," IEEE Trans. Antennas Propag., vol. 67 no. 8, pp. 4989 - 5001, 2019.

[27] M. K. Magill, G. A. Conway, and W. G. Scanlon, "Circularly Polarized Dual-Mode Wearable Implant Repeater Antenna With Enhanced IntoBody Gain," IEEE Trans. Antennas Propag., vol. 68 no. 5, pp. 3515 $3524,2020$.

[28] K. Zhang, Z. H. Jiang, W. Hong, and D. H. Werner, "A Low-Profile and Wideband Triple-Mode Antenna for Wireless Body Area Network Concurrent On-/Off-Body Communications," IEEE Trans. Antennas Propag., vol. 68 no. 3, pp. 1982 - 1994, 2020.

[29] H. Xiaomu, S. Yan, and G. A. E. Vandenbosch, "Wearable Button Antenna for Dual-Band WLAN Applications With Combined on and off-Body Radiation Patterns," IEEE Trans. Antennas Propag., vol. 65 no. 3 , pp. $1384-1387,2017$.

[30] J. Tak, S. Woo, J. Kwon, and J. Choi, "Dual-Band Dual-Mode Patch Antenna for On-/Off-Body WBAN Communications," IEEE Antennas Wireless Propag. Lett., vol. 15, pp. 1384 - 1387, 2015.

[31] X. Y. Zhang, H. Wong, T. Mo, and Y. F. Cao, "Dual-Band Dual-Mode Button Antenna for On-Body and Off-Body Communications," IEEE Trans. Biomed. Circuits Sys., vol. 11 no. 4, pp. 933 - 941, 2017.

[32] R. Masood, C. Person, and R. Sauleau, "A Dual-Mode, Dual-Port Pattern Diversity Antenna for 2.45-GHz WBAN," IEEE Antennas Wireless Propag. Lett., vol. 16, pp. 1064 - 1067, 2016.

[33] R. B. V. B. Simorangkir, Y. Yang, L. Matekovits, and K. P. Esselle, "Dual-Band Dual-Mode Textile Antenna on PDMS Substrate for
Body-Centric Communications," IEEE Antennas Wireless Propag. Lett., vol. 16 , pp. $677-680,2016$

[34] C. Mendes and C. Peixeiro, "A Dual-Mode Single-Band Wearable Microstrip Antenna for Body Area Networks," IEEE Antennas Wireless Propag. Lett., vol. 16, pp. 3055 - 3058, 2017.

[35] C.-X. Mao, D. Vital, D. H. Werner, Y. Wu, and S. Bhardwaj, "DualPolarized Embroidered Textile Armband Antenna Array With Omnidirectional Radiation for On-/Off-Body Wearable Applications," IEEE Trans. Antennas Propag., vol. 68 no. 4, pp. 2575 - 2584, 2020.

[36] X. Tong, C. Liu, X. Liu, H. Guo, and X. Yang, "Switchable ON/OFF-Body Antenna for $2.45 \mathrm{GHz}$ WBAN Applications," IEEE Trans. Antennas Propag., vol. 66 no. 2, pp. 967 - 971, 2018.

[37] S. J. Chen, D. C. Ranasinghe, and C. Fumeaux, "A Robust Snap-On Button Solution for Reconfigurable Wearable Textile Antennas," IEEE Trans. Antennas Propag., vol. 66 no. 9, pp. 4541 - 4551, 2018.

[38] G. Marrocco, "The art of UHF RFID antenna design: impedancematching and size-reduction techniques," IEEE Antennas Propag. Magazine, vol. 50, 1, pp. $66-79,2008$.

[39] M. Wagih, G. S. Hilton, A. S. Weddell, and S. Beeby, " $2.4 \mathrm{GHz}$ Wearable Textile Antenna/Rectenna for Simultaneous Information and Power Transfer," in 2021 15th European Conference on Antennas and Propagation, 2021.

[40] M. Wagih, O. Cetinkaya, B. Zaghari, A. S. Weddell, and S. Beeby, "Real-World Performance of Sub-1 GHz and 2.4 GHz Textile Antennas for RF-Powered Body Area Networks," IEEE Access, vol. 8, pp. 133746 $-133756,2020$.

[41] C. A. Balanis, "Antenna Theory: Analysis and Design. Third Edition," Wiley Interscience, pp. $830-833,2005$.

[42] C. Song, Y. Huang, P. Carter, J. Zhou, S. Yuan, Q. Xu, and M. Kod, "A Novel Six-Band Dual CP Rectenna Using Improved Impedance Matching Technique for Ambient RF Energy Harvesting," IEEE Trans. Antennas Propag., vol. 64, 7, pp. 3160 -3171, 2016.

[43] C. R. Valenta, M. M. Morys, and G. D. Durgin, "Theoretical EnergyConversion Efficiency for Energy-Harvesting Circuits Under PowerOptimized Waveform Excitation," IEEE Trans. Microw. Theory Techn., vol. 63 no. 5 , pp. $1758-1767,2015$.

[44] M. Wagih, A. S. Weddell, and S. Beeby, "High-Efficiency Sub-1 GHz Flexible Compact Rectenna based on Parametric Antenna-Rectifier CoDesign," in 2020 IEEE/MTT-S International Microwave Symposium (IMS), 2020.

[45] C. Song, Y. Huang, P. Carter, J. Zhou, S. D. Joseph, and G. Li, "Novel Compact and Broadband Frequency-Selectable Rectennas for a Wide Input-Power and Load Impedance Range," IEEE Trans. Antennas Propag., vol. 66, 7, pp. $3306-3316,2018$.

[46] J. W. Massey and A. E. Yilmaz, "Austinman and austinwoman: Highfidelity, anatomical voxel models developed from the vhp color images," in 2016 38th Annual International Conference of the IEEE Engineering in Medicine and Biology Society (EMBC), 2016.

[47] W. G. Whittow, A. Chauraya, J. C. Vardaxoglou, Y. Li, R. Torah, K. Yang, S. Beeby, and J. Tudor, "Inkjet-Printed Microstrip Patch Antennas Realized on Textile for Wearable Applications," IEEE Antennas Wireless Propag. Lett., vol. 13, pp. 71-74, 2014.

[48] M. Wagih, Y. Wei, A. Komolafe, R. Torah, and S. Beeby, "Reliable UHF Long-Range Textile-Integrated RFID Tag Based on a Compact Flexible Antenna Filament," Sensors, vol. 20 (12), p. 3435, 2020.

[49] K. Palmer and M. van Rooyen, "Simple broadband measurements of balanced loads using a network analyzer," IEE Transactions on Instrumentation and Measurements, vol. 55, no. 1, pp. 266 - 272, 2006.

[50] D. L. Paul, H. Giddens, M. G. Paterson, G. S. Hilton, and J. P. McGeehan, "Impact of Body and Clothing on a Wearable Textile Dual Band Antenna at Digital Television and Wireless Communications Bands," IEEE Trans. Antennas Propag., vol. 61 no. 4, pp. 2188 - 2194, 2013.

[51] M. Wagih, A. S. Weddell, and S. Beeby, "Meshed High-Impedance Matching Network-Free Rectenna Optimized for Additive Manufacturing," IEEE Open Journal of Antennas and Propagation, vol. 1, pp. 615 $-626,2020$.

[52] S. N. Daskalakis, G. Goussetis, S. D. Assimonis, M. M. Tentzeris, and A. Georgiadis, "A uW Backscatter-Morse-Leaf Sensor for Low-Power Agricultural Wireless Sensor Networks," IEEE Sensors J., vol. 18 no. 1, pp. $7889-7898,18$.

[53] A. Okba, A. Takacs, and H. Aubert, "Compact rectennas for ultra-lowpower wireless transmission applications," IEEE Trans. Microw. Theory Techn., vol. 67, 5, pp. 1697 - 1707, 2019.

[54] D. Balsamo, O. Cetinkaya, A. R. Arreola, S. C. B. Wong, G. V. Merrett, and A. S. Weddell, "A Control Flow for Transiently Powered Energy 
Harvesting Sensor Systems," IEEE J. Sensors, vol. 20 no. 18, pp. 10687 $-10695,2020$.

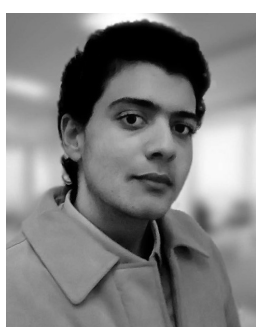

Mahmoud Wagih (GS'18) received his B.Eng. (Hons.) from the University of Southampton in 2018, where he is currently pursuing his Ph.D.

In 2017 he worked as a Research Assistant at the University of Southampton, investigating novel differential transmission lines. In 2018, he was a Hardware Engineering Intern at Arm, and, in 2020 a Research Intern at Arm, Cambridge, U.K. He is currently a Senior Research Assistant at the University of Southampton. His research interests lie in RF energy harvesting, wireless power transmission, RFID sensing, and wearable antennas. He has over 30 journal and conference publications and has delivered an invited webinar on these topics.

Mr. Wagih was the recipient of the Best Undergraduate Project Prize at the University of Southampton, in 2018, and was selected for the IEEE International Microwave Symposium Project Connect, 2019. He received the Best Student Paper Award at the IEEE Wireless Power Transfer Conference, 2019, and the Best Oral Paper at PowerMEMS, 2019. He received the Best 3MT Presentation Prize (second place) at the IEEE Microwave Week, 2020. $\mathrm{He}$ has acted as a reviewer for 7 journals including IEEE TRANSACTIONS on ANTENNAS AND PROPAGation.

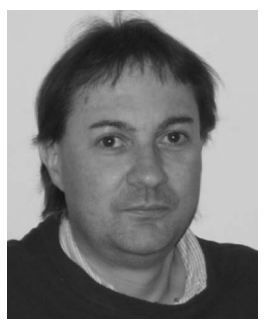

Geoffrey S. Hilton received the B.Sc. degree from the University of Leeds, Leeds, U.K., in 1984, and the Ph.D. degree from the University of Bristol, Bristol, U.K., in 1993, for research on the design and finite-difference time-domain modeling of printed antenna elements.

$\mathrm{He}$ is a Senior Lecturer with the University of Bristol. His current research interests include practical antenna and system design for a variety of communications and radar applications such as ground penetrating radar, performance evaluation of antennas in mobile radio, electrically small elements, active/tuneable elements, and vehicle-mounted conformal antennas.

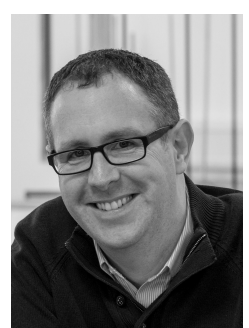

Alex S. Weddell (GS'06-M'10) received the M.Eng degree (1st class honors) and Ph.D. in electronic engineering from the University of Southampton, U.K., in 2005 and 2010.

His main research focus is in the areas of energy harvesting and energy management for future Internet of Things devices. He has over 14 years experience in design and deployment of energy harvesting systems, and has published around 55 peer-reviewed papers in the area. He is currently a Lecturer in the Center for Internet of Things and Pervasive Systems at the University of Southampton, and is involved with three projects funded by EPSRC, EU Horizon 2020 and Clean Sky 2.

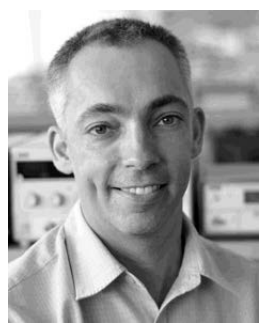

Steve Beeby received the B.Eng. (Hons.) degree in mechanical engineering from the University of Portsmouth, Portsmouth, U.K., in 1992, and the $\mathrm{Ph} . \mathrm{D}$. degree in MEMS resonant sensors from the University of Southampton, Southampton, U.K., in 1998.

He is currently the Head of the Smart Electronic Materials and Systems Research Group and leads the U.K.'s E-Textiles Network. He is currently leading three U.K. funded research projects and has received over 16 million research funding. $\mathrm{He}$ is a $\mathrm{Co}$ Founder of Perpetuum Ltd., a University spin-out based upon vibration energy harvesting formed in 2004, Smart Fabric Inks Ltd., and D4 Technology Ltd. He has co-authored/edited four books including Energy Harvesting for Autonomous Systems (Artech House, 2010). He has given 25 invited talks and has over 300 publications and 10 patents. He has an h-Index of 52. His current research interests focus on energy harvesting, e-textiles and the use of energy harvesting in wearable applications.

Prof. Beeby was the recipient of two prestigious EPSRC Research Fellowships to investigate the combination of screen-printed active materials with micromachined structures and textiles for energy harvesting and was also awarded a Personal Chair in 2011. He is currently the Chair of the International Steering Committee for the PowerMEMS Conference series. 